\title{
Single tunneling method with endoscopic submucosal dissection for treatment of a rectal giant $(18-\mathrm{cm})$ laterally spreading tumor
}

Endoscopic submucosal dissection (ESD) is an effective method for en bloc complete resection of lesions. We report a case of an $18-\mathrm{cm}$ laterally spreading tumor (LST) in the colon that was successfully removed by colorectal ESD using a tunneling technique.

The patient was a 61-year-old man who had a giant LST at the rectum starting $3 \mathrm{~cm}$ from the anal canal and extending proximally, measuring $13 \mathrm{~cm}$ endoscopically ( $\triangleright$ Fig.1). The procedure was performed after he had been sedated using spinal anesthesia. The lesion was examined by chromoendoscopy and endoscopic ultrasonography before ESD. The ESD strategy involved creating a tunnel from the anal site to a point proximal to the rectum, then joining the tunnel to the left part of the lesion using incision and dissection. Finally, the dissected part and the right part of the lesion were connected using incision and dissection assisted by gravity ( $\mathbf{F i g . 2}$, - Video 1). The time between the initial incision and the separation of the lesion from normal tissue was recorded as the duration of the procedure.

The resected tumor was removed en bloc and measured $179 \times 108 \mathrm{~mm}$ ( $\mathbf{F i g . 3}$ ). The procedure time was $224 \mathrm{~min}$. Examination of the pathological specimen showed intramucosal carcinoma, and all of the margins were clear. No complications occurred during or after the procedures ( $\$$ Fig.4). No residual tissue was seen on control colonoscopy ( $\downarrow$ Fig. $\mathbf{5}$ ).
The single tunneling technique may easily provide orientation during procedures with controlled dissection of huge lesions. In addition, this method can allow effective isolation and coagulation of the main blood vessels rather than vessel branches. Therefore, as excessive bleeding is prevented, it can help the endoscopist to obtain a cleaner submucosal layer and increase the quality of the procedure. We consider that these advantages may be beneficial for increasing the quality of the sample and removing huge lesions en bloc, decreasing the total procedure duration and helping the endoscopist to use operating time effectively.

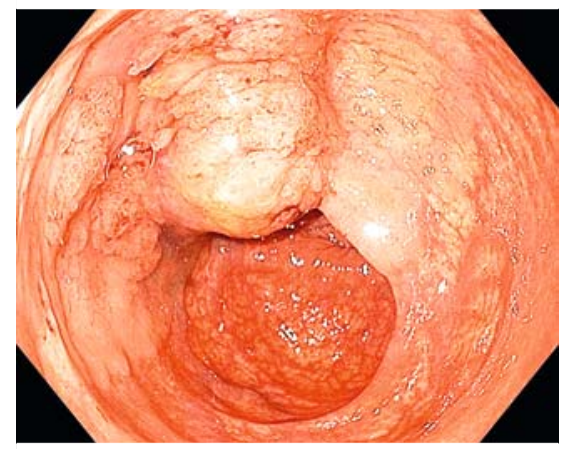

- Fig. 1 Giant laterally spreading rectal tumor in a 61-year-old man.
Endoscopy_UCTN_Code_TTT_1AQ_2AD

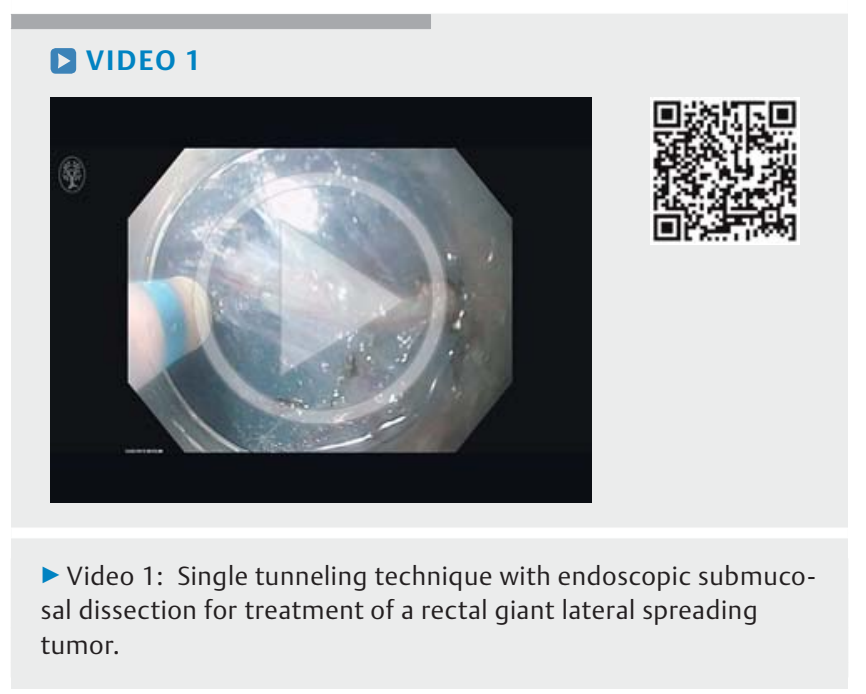




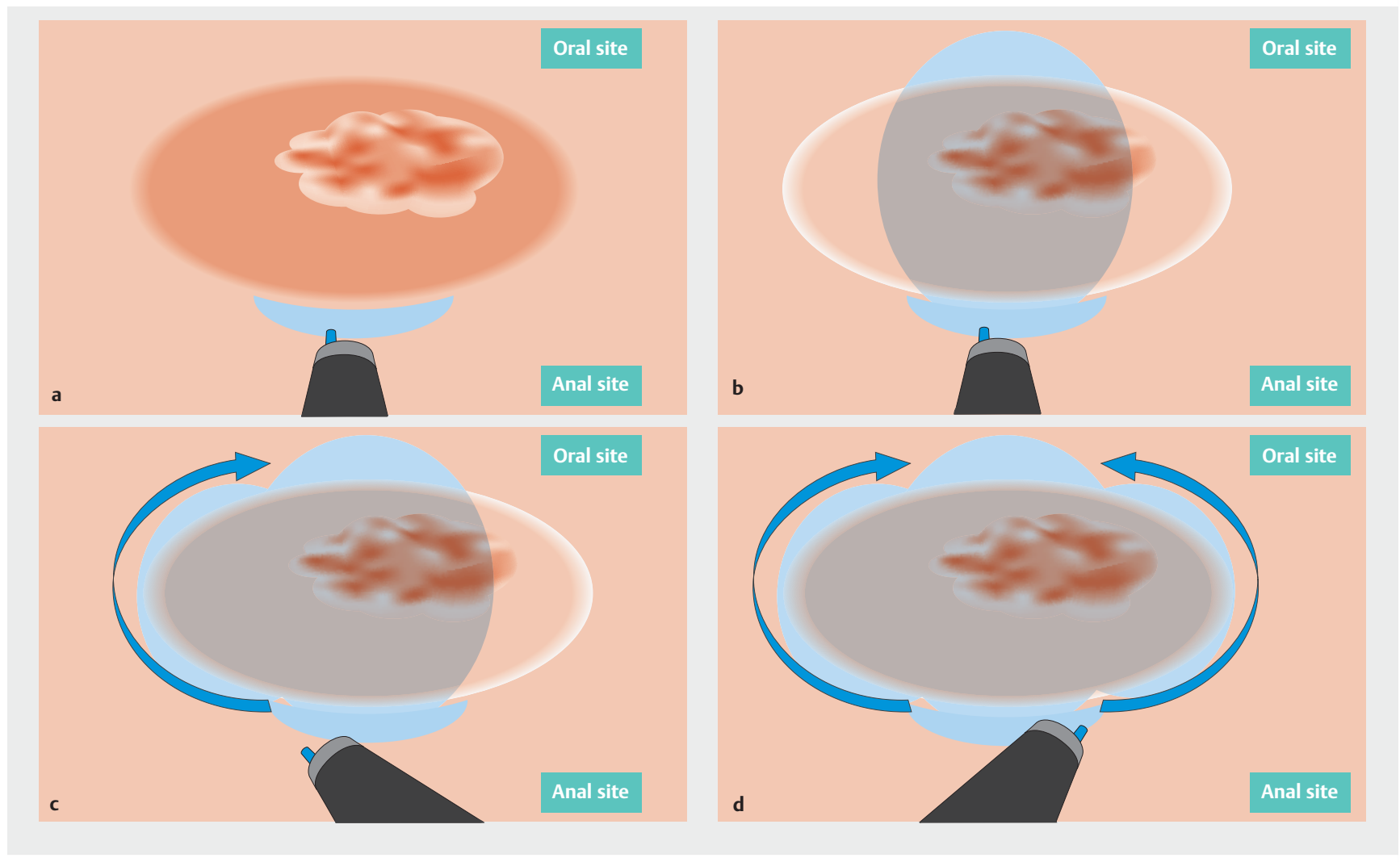

- Fig. 2 Endoscopic submucosal dissection strategy for tumor removal. a A short incision was made at the anal site of the lesion. $\mathbf{b}$ A tunnel was opened from the anal site to a point proximal to the lesion. $\mathbf{c}$ The tunnel was connected to the left part of the lesion using incision and submucosal dissection. $\mathbf{d}$ Incision and dissection were used to connect the dissected part of the lesion to the right part of the lesion.

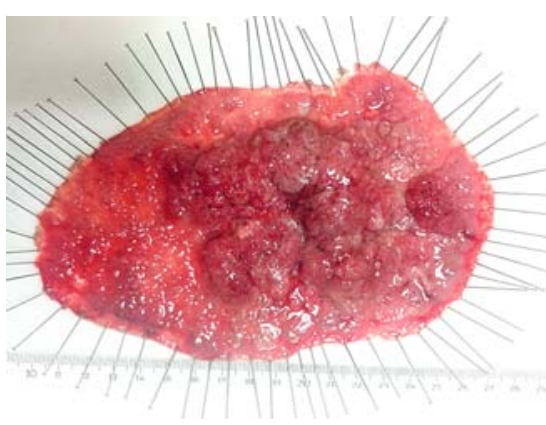

Fig. 3 The resected tumor was, $179 x$ $108 \mathrm{~mm}$ in diameter.

\section{Competing interests}

None

The Authors

Fatih Aslan', Zehra Akpinar', Derya A. Yurtlu², Melek Kucuk'1, Nese Ekinci³ ${ }^{3}$, Belkis Unsal ${ }^{1}$

1 Department of Gastroenterology, Izmir Ataturk Training and Research Hospital, Izmir, Turkey

2 Department of Anesthesiology and Resuscitation, Izmir Ataturk Training and Research Hospital, Izmir, Turkey

3 Department of Pathology, Izmir Ataturk Training and Research Hospital, Izmir, Turkey

\section{Corresponding author}

\section{Fatih Aslan, MD}

Yali Mahallesi, I. Tarik Sari Caddesi, Aktas Evleri-1, B Blok, No: 16, Daire: 5, 35310, Guzelbahce, Izmir, Turkey Fax: +90-232-2431530

drfatihaslan@hotmail.com 

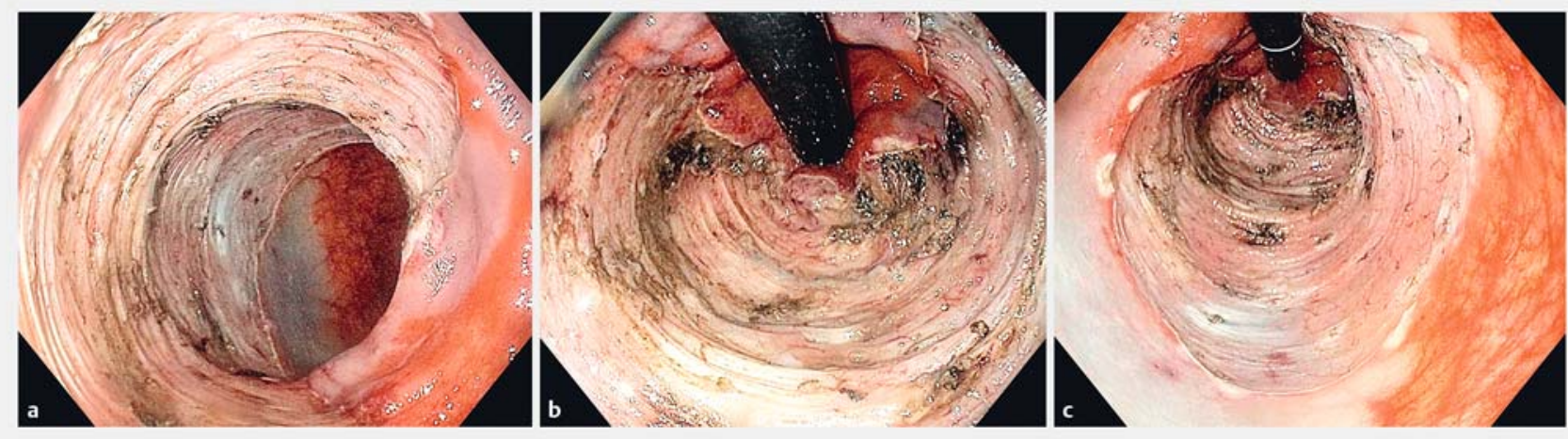

Fig. 4 a-c The area of endoscopic submucosal dissection after resection of the tumor.
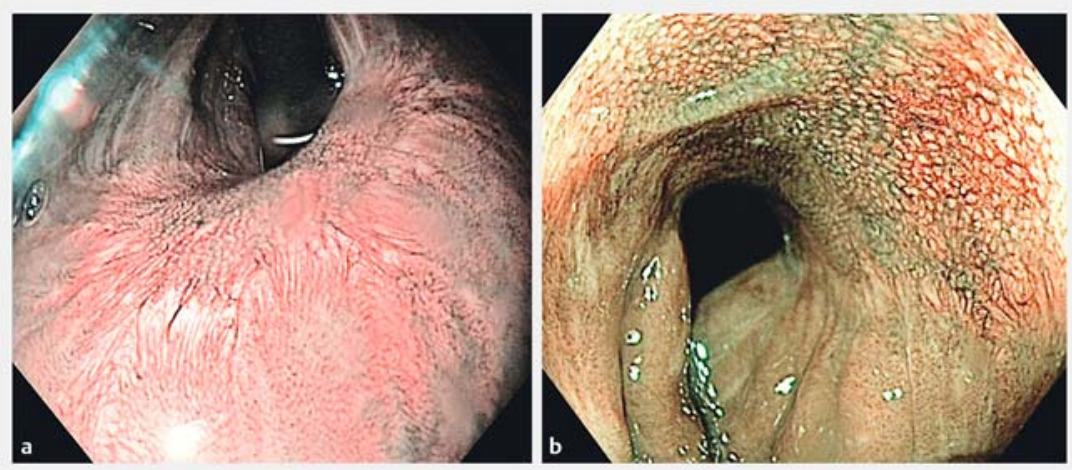

\section{Bibliography}

DOI http://dx.doi.org/10.1055/s-0043-100218

Endoscopy 2017; 49: E114-E116

(c) Georg Thieme Verlag KG

Stuttgart $\cdot$ New York

ISSN 0013-726X

> Fig. $\mathbf{5}$ a, b The resected area after 6 months. 